\section{EMBRYRIDDLE Aeronautical University}

SCHOLARLY COMMONS
International Journal of Aviation, Aeronautics, and Aerospace

\title{
A Novel Approach for Missing Combat Support Aircraft Search Acceleration using VTOL UAS
}

\author{
Mohammed Ba Zuhair \\ Kazan National Research Techincal University, mohammed-ba@yandex.ru \\ Wisam Yousef \\ Research Assistant, Kazan National Research Technical University - KAl, Kazan, Russia, wyasen@mail.ru \\ Issam Samara \\ PhD researcher, Don State Technical University, Rostov-Na-Donu, Russia, samaraissam@gmail.com \\ Vladislav Varsegov \\ Assoc. Professor, Kazan National Research Technical University - KAl, Kazan, Russia, varvl@mail.ru
}

Follow this and additional works at: https://commons.erau.edu/ijaaa

Part of the Aeronautical Vehicles Commons, Aviation Safety and Security Commons, and the Management and Operations Commons

\section{Scholarly Commons Citation}

Ba Zuhair, M., Yousef, W., Samara, I., \& Varsegov, V. (2018). A Novel Approach for Missing Combat Support Aircraft Search Acceleration using VTOL UAS. International Journal of Aviation, Aeronautics, and Aerospace, 5(4). https://doi.org/10.15394/ijaaa.2018.1269

This Position Paper is brought to you for free and open access by the Journals at Scholarly Commons. It has been accepted for inclusion in International Journal of Aviation, Aeronautics, and Aerospace by an authorized administrator of Scholarly Commons. For more information, please contact commons@erau.edu. 


\section{A Novel Approach for Missing Combat Support Aircraft Search Acceleration using VTOL UAS}

\section{Cover Page Footnote}

This work is initially proposed and developed within the framework of Airbus international contest "Fly Your Ideas 2017". We are grateful to Airbus experts Laurent B. and Laval C. for their supervision and valuable discussions on FLB design criterions, ejection system maintainability and overall operation optimization. 


\section{Introduction}

Recently, aviation history witnessed the two most costly search operations to localize and recover AF447 and MH370 wreckage along with their flight data and cockpit voice recorders, i.e. (FDR) and (CVR). According to final reports, the total cost of the search campaign for AF447 was $\$ 44 \mathrm{~m}$ (Bureau of Enquiry and Analysis for Civil Aviation Safety, 2012), while the cost of the second ongoing search operation for MH370 is \$198m (Australian Air Transport Safety Bureau, 2017). These and many other difficulties encountered during search operations have revealed the inadequacy of the existing flight data recovery technologies, especially for accidents over oceanic or remote areas. Thus, following the AF447 air crash, many high-level technical groups have been organized for assessing technical options and formulating modernized requirements to achieve aircraft active tracking, emergency alerting, wreckage localization, and flight data recovery (Bureau of Enquiry and Analysis for Civil Aviation Safety, 2009). As a result, a leap towards real-time tracking of airborne commercial flights en route was achieved in 2016 when the International Civil Aviation Organization (ICAO) announced the partnership of Aireon and Flightaware to launch GlobalBeacon, a solution to provide $100 \%$ global on-line flight tracking by 2018 without modifying the existing avionics. The service merges space-based Automatic Dependent Surveillance Broadcast (ADS-B) aircraft surveillance network owned by Aireon with the flight tracking web interface provided by Flightaware. This service will secure open access to flight origin, destination, plan route, position, and estimated time of arrival as well as an immediate notification of abnormal in-flight events to airlines and air traffic controllers (FlightAware, 2016).

Unfortunately, current supplementary components attached to flight data recorders such as underwater locator beacons (ULBs) suffer of short battery lifetime which limits acoustic signal transmission to 30 days. Hence, according to the updated European Aviation Safety regulations on air operations, it is already required that the transmission time of ULBs be extended to 90 days by 2020. Moreover, starting in January 2019 most large commercial aircraft operating over routes that exceed $333.36 \mathrm{~km}$ from shore are obliged to become equipped with an additional airframe low-frequency $(8.8 \mathrm{KHz})$ ULBs for enabling very long detection range. Fundamentally, the combination of both descried approaches will undoubtedly alleviate the strenuous effort occasionally conducted to locate a missed commercial aircraft body. Also, it will increase the probability of spotting its FDR and CVR, which is now $90 \%$ (Wang, Hung, Ho, Lin, \& Yeh, 2015).

In practice, aforementioned measures only apply to commercial aircraft linked to FlightAware global datalink. For combat support aircraft with fuselage mid-section bigger than six meters including military transport 
aircraft and air-to-air refueling aircraft, flight data broadcasting and reception by ground personnel at high frequencies, e.g. at $1090 \mathrm{MHz}$, characterizes merely routine flights. However, precautionary procedures proceed entering combat modes and pilots are minutely instructed to turn off all transponders to achieve invisibility to ADS-B and traditional secondary radars (ADS-B Exchange, 2017). In result, such procedures significantly complicate the precise real-time flight path tracking leading, sometimes, to a laborious search operation in case such an aircraft is announced missed.

In addition, analysis of 49 commercial aircraft accidents dating from 1980 until 2016 (see Figure 1) revealed that no matter how quickly crash location is identified, retrieval of FDR and/or CVR lasts few days in average, especially when the airframe tears apart. This indeed consumes the first invaluable time for the investigators. Unlike the ones on the current commercial aircraft, deployable free-floating flight recorders are widespread on helicopters, a combat support aircraft. They are characterized by better activation, survivability, and radio signal transmission record than undeployable models (Dhananjay, Suraj, \& Meenakshi, 2015). Installation of deployable recorders in the in-service and future commercial aircraft has been evaluated in detail by DRS, GE, Boeing, and recently adopted by Airbus for its medium and long range jet airliners (Bureau of Enquiry and Analysis for Civil Aviation Safety, 2012; Consumer News and Business Channel, 2017). These devices, in addition to the upcoming real-time flight tracking solutions, will build a robust system for efficient search campaigns of missed commercial aircraft.

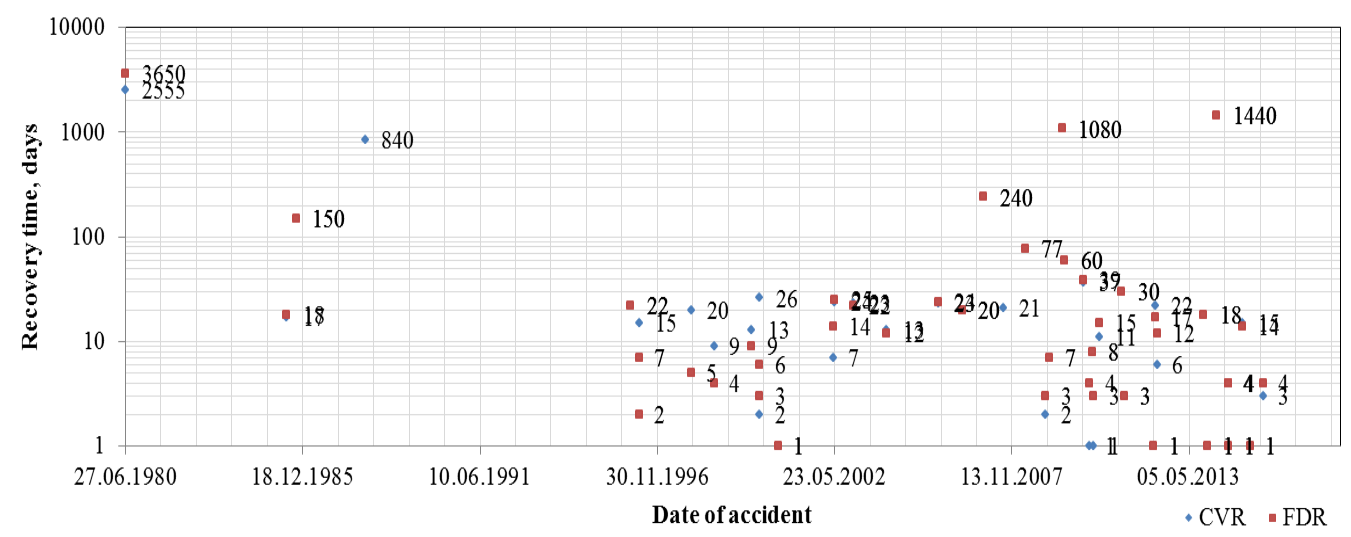

Figure 1. FDR and CVR recovery time, days, see (Bureau of Enquiry and Analysis for Civil Aviation Safety, 2012) and (Aviation Safety Network, 2018).

Again, in military situations in-flight calamities for combat support aircraft are transmitted by crew reports causing instant flight coordinates delay. In case of its disappearance any search operation will require more, usually unavailable, time to scan a possible crash area and successfully 
localize bodies, wreckage, and flight recorders. As such, during severe and tense war circumstances long delays in search operations must be anticipated. Consequently, an increase of deployable flight recorders batteries service time to 90 days may not significantly speed up finding a missing combat support aircraft.

Accordingly, a new approach should be developed to meet the specific requirements of combat support aircraft operation, provide short-time and lowcost localization of their crash points, and safeguard their flight data. This paper briefly outlines flight data preservation and recovery project for conceptualizing, modelling and testing of a combat support aircraft search system that utilizes only global positioning system (GPS) data received by a vertical takeoff and landing (VTOL) unmanned aerial system (UAS) to accelerate search operations.

Below, the paper firstly outlines overall system architecture and dynamics, where the second section describes the on-board hardware requirements, design criterions, and configuration. The third section is dedicated to capturing the operational processes after detecting a catastrophic event on-board.

\section{Hardware configuration}

FDR and CVR represent a pivotal source for investigators in the identification process of the factors behind an air accident. These days, most of them are installed in the empennage since it has the highest probability of survival in crash scenarios (National Transportation Safety Board, 2017). Thus, the same location inside the Soviet airliner Il-86 airframe is chosen for mounting this proposed flight data recovery system as shown in Figure 2. Currently, this aircraft is out of service for commercial purposes, though it remains being limitedly operated by air forces in Russia and few post-Soviet states. Besides, on-line access to its documentation (Bekhtir, 1991) and experimental data (Aviation Library, 2017) really facilitates further computational and mathematical modelling.

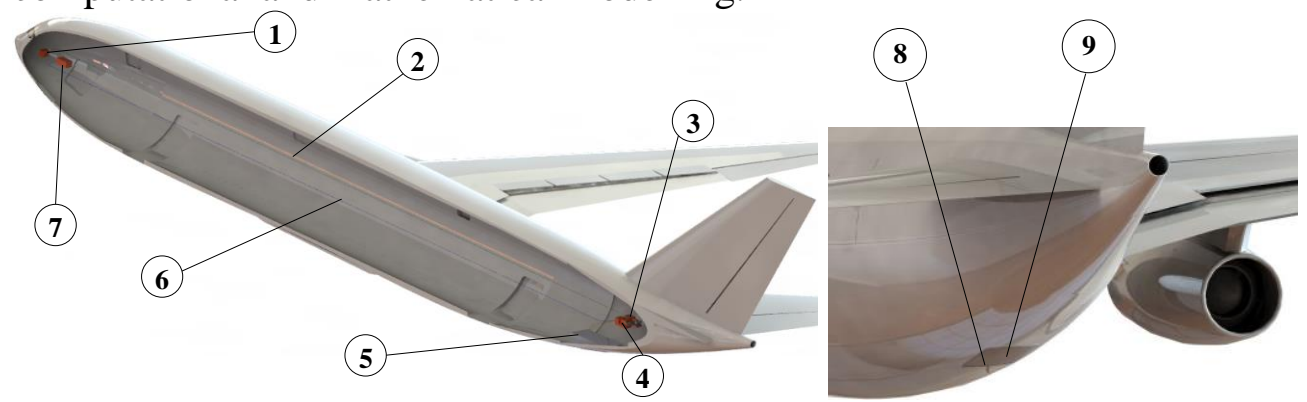

Figure 2. Airborne components of the secondary flight data recovery system; 1 - cockpit voice acquisition unit; 2,6 - cables; 3 - cockpit voice recorder; 4 flight data recorder; 5 - ejection system; 7 - flight data acquisition unit; 8 ejection system transmitter; 9 - ejection hatch. 
In general, the secondary flight data recovery system comprises two subsystems: Unmanned Aerial System (UAS) or so-called "Flying Locator Beacon (FLB)" and its Ejection System (ES). The scope of this paper is to focus on FLB and its post-ejection operations since further detailed description and analysis of ES operability, survivability, reliability, and maintainability will need a separate work. However, it is indeed worthy to provide a brief overview on ES, which implies a chamber for FLB long-term storage and rapid ejection during extreme emergencies. Automatic ejection command is the output of exceeding certain predefined parameters for each aircraft type according to a conditional function $\left(F_{E}\right)$

$$
\sum F_{E}\left(V_{y}, T_{i}, \ldots, f_{\text {airframe }}\right) \leq\left\{\begin{array}{l}
F_{E}\left(\bar{V}_{y}^{H_{0}}\right) \\
F_{E}\left(\bar{T}_{i}^{H_{0}}\right) \\
. \\
\ldots \\
F_{E}\left(\bar{f}_{\text {airframe }}^{H_{0}}\right)
\end{array}\right.
$$

where $V_{y}, \bar{V}_{y}^{H_{0}}-$ aircraft vertical speed and its limit, respectively; $T_{i}, \bar{T}_{i}^{H_{0}}$ temperature $\left(T_{i}\right)$ inside $i$ compartment(s) that must be less than $\bar{T}_{i}^{H_{0}} ; f_{\text {airfame }}-$ registered airframe vibration and its upper limit $\left(\bar{f}_{\text {airfame }}^{H_{0}}\right)$. All limits restrict triggering function to condition violations occurring below ejection flight level ( $H_{0}$ ) equal to $H_{0}=1500 \mathrm{~m}$ for a given duration. ES location may vary in different aircraft, which depends on the layout of the tail section. Preliminary ES location is below the Auxiliary Power Unit (APU) of Il-86. This choice minimizes its necessary design modifications, avoids deteriorating its aerodynamic performance, and increases ES survivability.

ES is composed of a catapulting or propelling device, separate power unit, navigational instruments (three-axial accelerometer, gyroscope, pressure altimeter, GPS module, etc.) used to track main flight parameters until crash, a transmitter to deliver those data to FLB, ES hatch release mechanism, and diagnostics unit. For ES hatch the widely implemented pyromechanical devices for space rockets and jet fighter canopy release systems are suggested due to their light weight, very high reliability and quality, proven safety in addition to the instantaneous reaction compared to other investigated mechanisms (Chemring Co., 2012).

\section{Flying Locator Beacon (FLB)}

The threat of losing combat support aircraft with on-board FDR and CVR increases during military activities. This drawback may be effectively outflanked once the said devices gain mobility to some appointed safe locations. For this purpose, FLB, main FLB conceptual design specifications 
of which are listed in Table 1, is introduced as a reserve flight data recorder with synchronized duplication of input data to FDR and CVR that will be extracted to a certain point projected on the global Geographic Coordinates System (GCS). This point, henceforth, will be abbreviated as the Landing Point "LP," is the integer value of the closest latitude and longitude coordinates to the ejection coordinates. Therefore, when considering all the integer values of latitude and longitude coordinates, i.e. 360 and 180, the total number of LPs being distributed on the entire surface of Earth is $360 \times 180=$ 64800 .

Table 1

FLB Specifications.

\begin{tabular}{|l|l|}
\hline \multicolumn{1}{|c|}{ Specifications } & \multicolumn{1}{c|}{ Value } \\
\hline Dimensions, $\mathrm{m}$ & $0.5 \times 1.2 \times 0.3$ \\
\hline Wingspan, $\mathrm{m}$ & 1.2 \\
\hline Wing area, $\mathrm{m}^{2}$ & 0.14 \\
\hline Aspect ratio & 6 \\
\hline Weight, kg & 3 \\
\hline Powerplant & DC Brushless motors \\
\hline Cruise speed, $\mathrm{m} / \mathrm{s}$ & 105 \\
\hline Endurance, $\mathrm{min}$ & $\sim 100$ \\
\hline Service ceiling, $\mathrm{m}$ & 1500 \\
\hline
\end{tabular}

Generally, maximum flight path ( $L_{\max }$ ) for FLB to travel from an ejection point at $H_{0}$ to the furthest LP halves the orthogonal between two GCS points on the equator ( $\left.L_{G C S}\right)$ as $L_{\max }=\sqrt{\left(0.5 \sqrt{2 \cdot L_{G C S}^{2}}\right)^{2}+H_{0}^{2}} \mathrm{~km}=78.503 \mathrm{~km}$, where $L_{G C S}=111 \mathrm{~km}$. This, being the longest possible flight path, represents the worst FLB flight scenarios in stable weather conditions. With given FLB weight $(W)$ and wing area $(A)$ descent speed $V_{D E S}$ is determined as $V_{D E S}=\sqrt{2 W / C_{l_{D E S}} \rho A}$ for sea level atmospheric conditions with $C_{l_{D E S}}\left(\alpha_{D E S}\right) \approx 0.4$. To maintain low spanwise loading $\alpha_{D E S}$ is controlled at $\sim 3 \mathrm{deg}$. Swift penetration through the possible turbulent flow around the empennage during violent descents is achievable by providing an initial speed using propulsive unit. Besides, VTOL capability stems from the operational requirement to facilitate landings on small spots. Configuration selection seeks a relatively short wingspan to enhance storability inside a fuselage with mid-section wider than $6 \mathrm{~m}$. Since water surface landings are inevitably to occur waterproofing and buoyancy by 
full sealing of FLB airframe are crucial. In combination, these requirements synthesize the main FLB conceptual design input criterions.

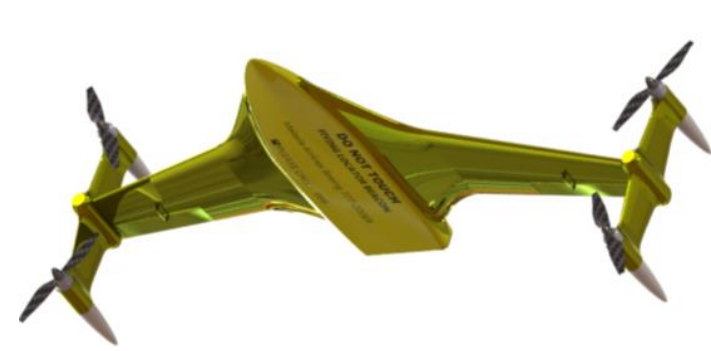

Figure 3. FLB 3D model.

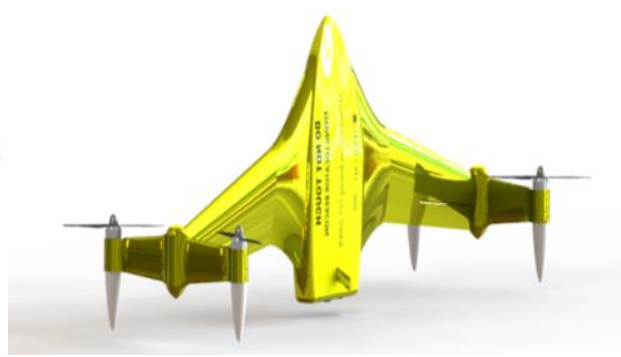

FLB airframe material is 1060 aluminium alloy with skin thickness of $\sim 1 \mathrm{~mm}$ ensuring enough stiffness with lightweight structure. Additional shock absorbing case protects the inner memory chip. Modular layout, where fuselage, half-wings, winglets are manufactured and assembled as separate shells attachable by bolts enhances survivability and buoyancy in case of local structural failures. This initial research aims at modelling and validating main FLB performance in normal and abnormal flight conditions as well as assessing basic survivability/recoverability, therefore fully integrated circuit board with FDR and CVR memory chips, processing unit and other components have not been adopted yet merely from a financial perspective. Full-scale design should follow successful field tests. Instead, available commercially-off-the-shelf elements in Figure 4 are used. Patient and careful wiring and system compatibility is considered. Inappropriate use of wire size and connectors would, of course, increase the end product weight and volume. It may even burn, damage, or at least increase power loss (Parvathy \& Howard, 2014). The high thrust-to-weight ratio requirement for VTOL is met by installing four MIN1806 Kv1400 brushless motors with a total maximum power $128.8 \mathrm{~W}$ and 3 in radius carbon fiber blades mounted using propeller adapters. The motors are connected using bullet connectors with Electronic Speed Controllers (ESCs). A pair of $0.350 \mathrm{~kg} 7.5 \mathrm{Ah} \mathrm{Li-Po} \mathrm{batteries} 7.4 \mathrm{~V}$ and lightweight 11.6Ah Li-ion batteries with $7.4 \mathrm{~V}$ are selected to power FLB electrical components and electronics via Power Distribution Board (PDB), meanwhile overcharging and over-discharging is prevented by embedding Protective Circuit Board (PCB). Autonomous flight control program is run using high-performance Pixhawk autopilot 32bit STM32F427 Cortex M4 core with Floating Point-Unit (FPU). The autopilot is equipped with integrated ST Micro L3GD20H 16-bit gyroscope, ST Micro LSM303D 14 bit accelerometer, magnetometer Invensense MPU 6000 3-axis accelerometer/gyroscope, and MEAS MS5611 barometer, which, indeed, decreases the weight and work needed for design and connections. 
To enable yawing and pitching moment control elevons deflectable by $4.8 \mathrm{~V}, 1.6 \mathrm{~kg}-\mathrm{cm}$ servos and connected with the appropriate Servo Speed Regulators (SSR) for smooth longitudinal and lateral maneuverability are adopted. Deferential throttling of motor pairs at each side ensures directional maneuverability. For monitoring and FLB real-time tracking in the framework of this preliminary research, Eagle Tree System Flight Data Recorder (ETSFDR) and transmitter are used. FLB flight data are transmitted to a ground-based ETS receiver with USB connection to a portable computer for further analysis. Obviously, steep vertical landing on liquid and solid surfaces requires precise proximity feedback that is supported by an ultrasonic distance measuring sensor mounted in the tail section and switched on only within VTOL modes. Occasionally, night search operations for FLB to be likely undertaken and true short visibility should be enhanced by means of yellow painting and LED wingtip navigation lights.

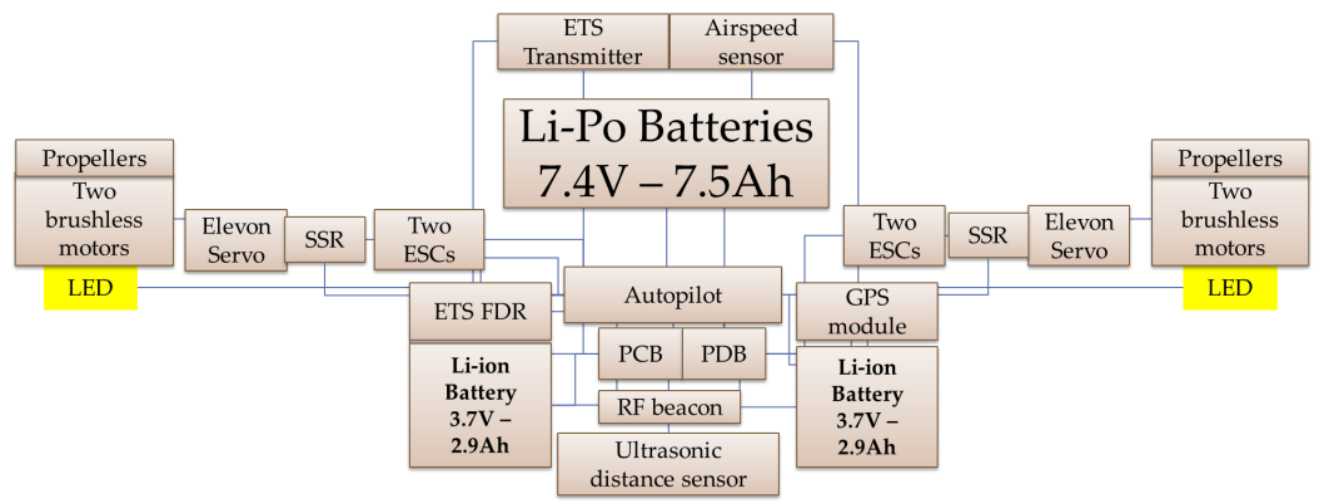

Figure 4. FLB components and electronics.

Today, remarkable advances in development and application of numerical analysis and simulation tools have led to significant cuts in conceptual design budgets especially in aeronautical and aerospace industries. Their optimal exploitation for obtaining a quick understanding of UAS aerodynamic and structural characteristics delivers fast, accurate and valuable data for further performance mathematical modelling. In the framework of this research CFD tool ANSYS Fluent 15.0 is used for FLB geometry and streamlining optimization. Figure 5 demonstrates aerodynamic coefficients diagrams, where $\mathrm{Cl}$ and $\mathrm{Cd}$ stand for lift force and drag coefficients respectively for given angles of attack $(\alpha)$ pertaining to non-vertical flight. 

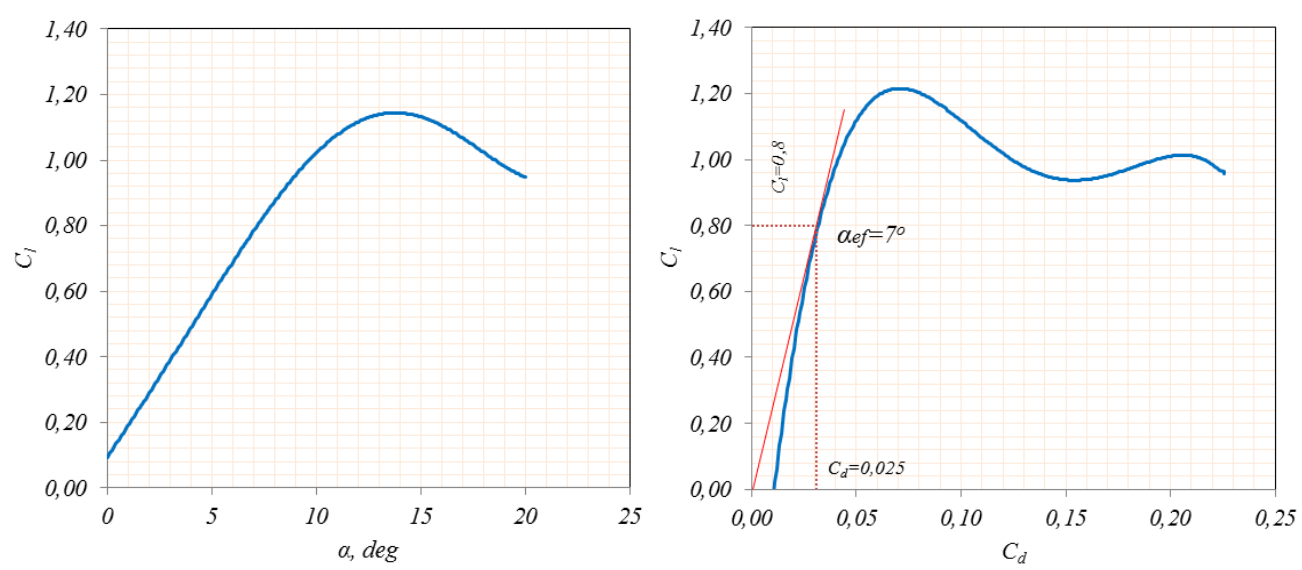

Figure 5. $C_{l}(\alpha)$ and $C_{l}(\alpha) / C_{d}(\alpha)$ diagrams.

It is obvious that the relatively small critical $\alpha_{c r}$ at $12^{\circ}-13^{\circ}$ is directly caused by the leading-edge curvature and the absence of high-lift devices. However, the chosen quadcopter propulsion scheme provides high maneuverability and stall control. Considering FLB purpose only one-time flight is expected to be conducted and mostly governed by horizontal flight at the efficient angle of attack $\left(\alpha_{e f}\right)$, see Figure 5. Descent angle $\left(\theta_{D E S}\right)$ towards LP is given as $\theta_{D E S}=\arctan \left(\frac{H_{0}}{L_{L P}}\right)$. In stable weather conditions worst scenario estimates $T_{D E S}=L_{\max } / V_{D E S} \approx 45 \mathrm{~min}$. Of course, turbulent atmospheric medium, particularly strong wind and rain, significantly affects this estimation. However, FLB autopilot algorithm generally considers either flying during predefined operational conditions or performing direct landing on the current site. Detailed analysis and discussion of the relevant flight dynamics and automatic control and control establishes the content of a further work. Here, the main flight modes currently under investigation are outlined, which are descent and vertical landing. Descent time and range vary as a function of distance between ejection point and LP as well as the generated lift force whilst descending. Zero or small $\theta_{D E S}$ attains economical flight over large flight paths. On the contrary, vertical landing attitude requires gradual pitching to set perpendicular position relative to the ground allowing quadcopter landing, where lift force becomes exclusively generated by the motors.

In general, hovering should be invariably shortened because it consumes ravenously the remaining power that should be instead used for location broadcasting extension. Calculation for the worst scenario that includes steep flight, hover and vertical landing with Li-Bo batteries power supply at estimated $T_{H}=10 \mathrm{~s}$ and $H_{L}=7.5 \mathrm{~m}$ at $V_{V}=-0.5 \mathrm{~m} / \mathrm{s}$ requires $P_{D E S} \approx 33.7 W, P_{H} \approx 392 W, P_{V} \approx 377 W$ predicts preserving: 


$$
C=C_{0}-C_{\text {cons }}=C_{0}-\frac{1}{U}\left(\frac{L_{\max }}{V_{D E S}} P_{D E S}+T_{H} P_{H}+\frac{H_{L}}{V_{V}} P_{V}\right) \approx 3.4 \mathrm{Ah}
$$

where $C_{0}$ - total batteries capacity; $C_{\text {cons }}$ - consumed battery capacity; $U-$ motor voltage; $P_{D E S}$ - power required for steep descent; $T_{H}$ - hover durance; $P_{H}$ - power required for hovering; $V_{V}$ - vertical landing speed; $H_{L}-$ landing altitude; $P_{V}-$ power required for landing.

After landing, FLB activates calling mode, where only pulsing radio frequency (RF) beacon at the front part of FLB is set to operate on Li-ion batteries. This enables over 30 days of signal transmission of $50 \mathrm{~km}$ radius every one minute according to $T_{T R}=C / \xi I_{\text {transmitter }}$, where $\xi=1 / \mathrm{t}_{R F}=0.017$ is factor stating pulses gap in seconds, here $t_{R F}=60 \mathrm{sec}$ and $I_{\text {transmitter }}$ stands for transmitter current per pulse. Transmission range and duration improvements yields pulsing period dilation using power remaining from the main power sources, which can beexploited using preprogrammed settings. LP geographical properties, e.g. terrain and vegetation, influence in an unpredictable manner transmission quality and range too.

\section{Operation}

\section{Post-Ejection Flight}

After ejection FLB decelerates from ejection speed $V_{e j}$ to $V_{D E S}$. Figure 6 shows the required catapulting force for a range of ejection process parameters.

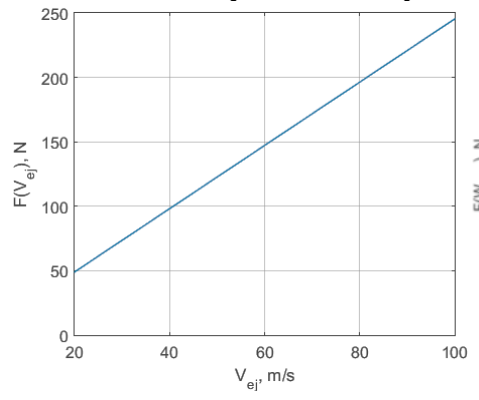

Figure $6 a$

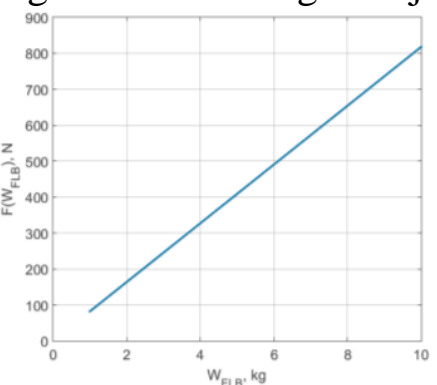

Figure $6 b$

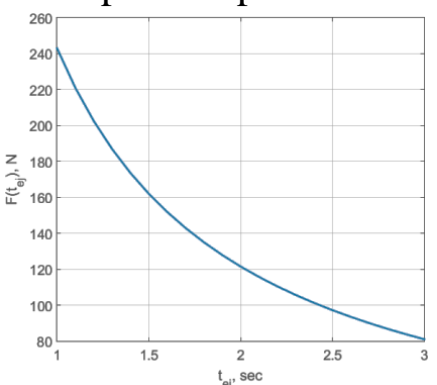

Figure $6 c$

Figure 6. Required catapulting force as a function of ejection speed (Figure 6a), FLB weight (Figure 6b), and ejection period (Figure 6c).

In Figure 6a ejection force is proportional to the chosen ejection speed $\left(V_{e j}\right)$.

Its optimum choice should ensure lowering structural spanwise loading and alleviating control disturbances caused by the potential turbulent flows at the tail zone. Figure $6 \mathrm{~b}$ shows the scale of dynamic propelling force to overcome FLB inertial force per each increment of weight $\left(W_{F L B}\right)$ in kilograms. Certainly, ejection period $\left(t_{e j}\right)$ tops as a critical parameter making tangible 
difference in FLB survivability. However, $t_{e j} \square 1 \mathrm{sec}$ applies high tangential loading to FLB parts that should be averted.

Once deployed, FLB approves its current coordinates input from ES before ejection. If the vertical coordinate representing altitude $(H)$ reading satisfies $H \geq H_{0}$ further calculation of LP is conducted. To define the closest LP autopilot collects inputs from the GPS module. Latitude and longitude of the ejection point are rounded to the closest integer value without mantissa part, see Figure 7.

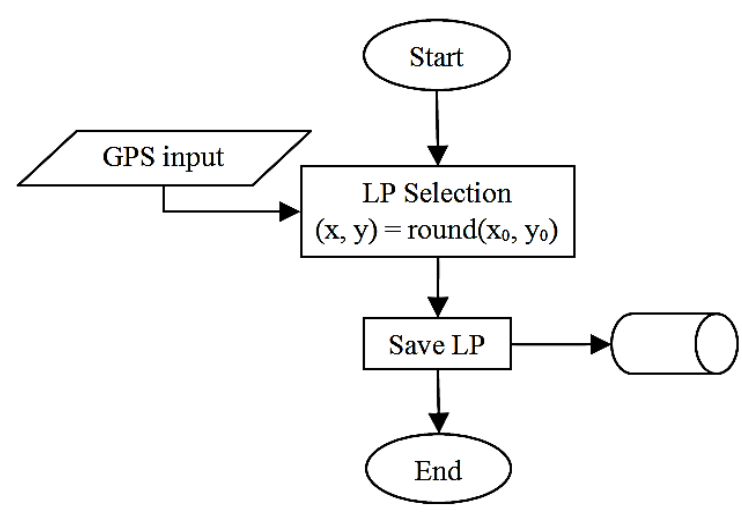

Figure 7. LP selection algorithm.

If $H<H_{0}$ climb up procedure to $H_{0}$ is prioritized to avoid collision with ground-based high objects such as mountains, towers, etc. When $H=H_{0}$ condition is met LP calculation loop is activated. Distance between the current latitude $x_{0}$ and longitude $y_{0}$ and chosen LP determines $\theta_{D E S}$ and $L_{L P}$. Flight route reference points or so-called "waypoints" ( $\left.N_{\text {Ref }}\right)$, where $N_{\text {Ref }}=L / L_{\text {ref }}$ are also become assigned for heading accuracy verification per ten seconds, which is equivalent to $L_{r e f}=0.3 \mathrm{~km}$. Deviation margin $(\Lambda)$ from waypoints must realize $\Lambda_{0} \leq 15 \mathrm{~m}$. If more, FLB autopilot runs landing procedure since frequent or unrecoverable $\Lambda>\Lambda_{0}$ indicates unsafe abnormal flight conditions caused by atmospheric medium instability. Such an immediate landing locates FLB near aircraft crash point facilitating FLB subsequent search operation. The main flight algorithm is shown in Figure 8. 


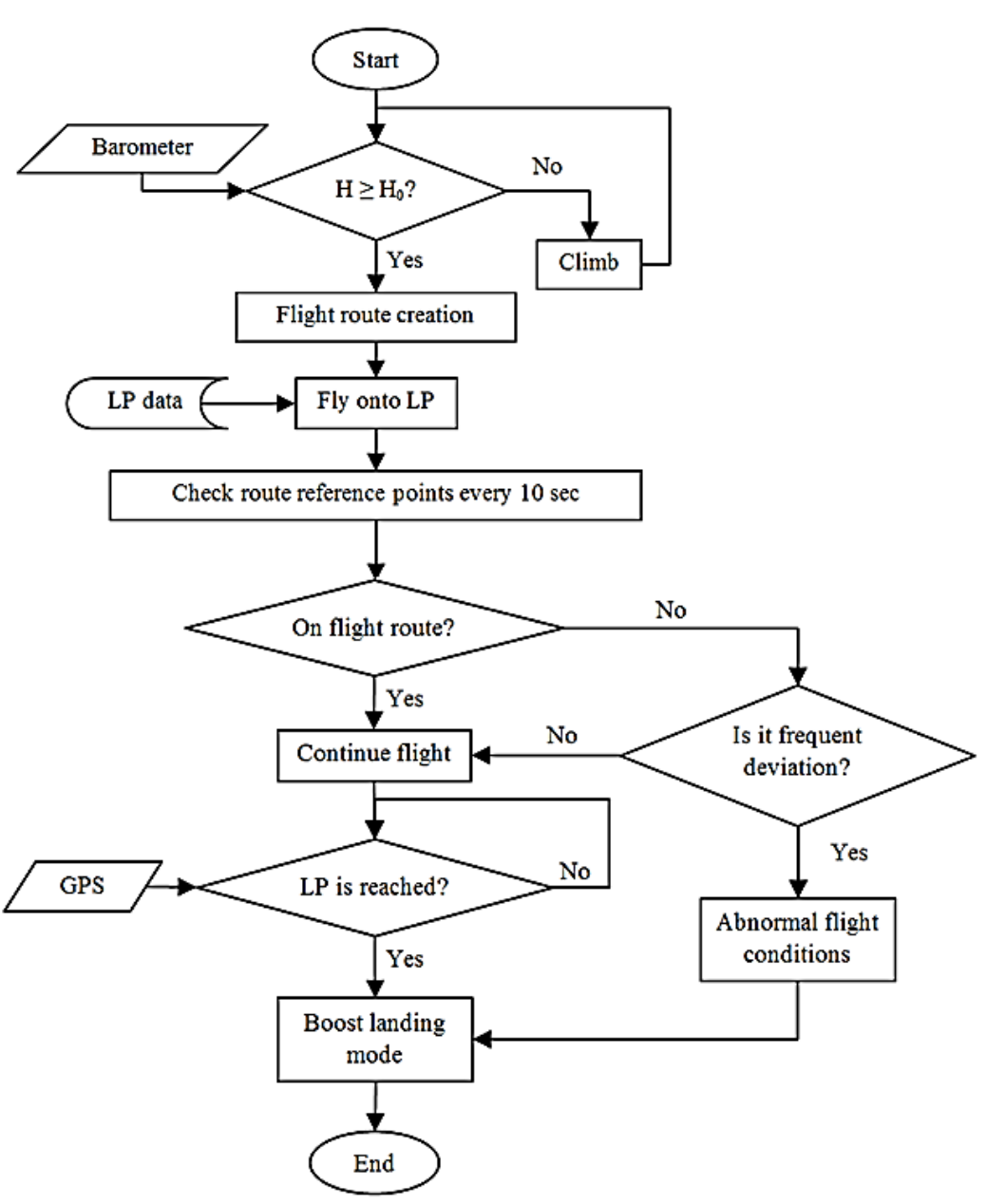

Figure 8. Main flight algorithm.

This paper outlines overall characteristics and specifications of the suggested system components. Consequently, FLB flight dynamics, control, and optimization besides aerodynamics and structural dynamics detailing for different operational conditions along with compatibility and aircraft-FLB interactive dynamics are subjects of later dedicated works. Below, due to current unavailability of combat support aircraft crash detailed data Figure 9 shows simulation FLB deployment from AF447 experiencing nosedive at 16 deg with $200 \mathrm{~km} / \mathrm{h}$ (Bureau of Enquiry and Analysis for Civil Aviation Safety, 2012). It demonstrates $L$ change along $x$-axis $\left(L_{x}\right)$ and y-axis $\left(L_{y}\right)$ starting from the ejection point at $(-30.561667,3.0658333)$ (Bureau of Enquiry and Analysis for Civil Aviation Safety, 2012) and 40m/s up to the closest LP with coordinates $(-310000,+030000)$ and altitude change per time unit $(\mathrm{t})$ in minutes for AF447 crash when steady weather conditions are assumed for this stage of the research. Note that in the real scenario windy $(\sim 10 \mathrm{~m} / \mathrm{s})$ and rainy weather were concluded, though could not critically endanger the A330 carrying flight number AF477 (Vasquez, 2011), however it indeed could badly affect FLB trim and stability resulting in constant path deviation and hardly controllable landing on water. 


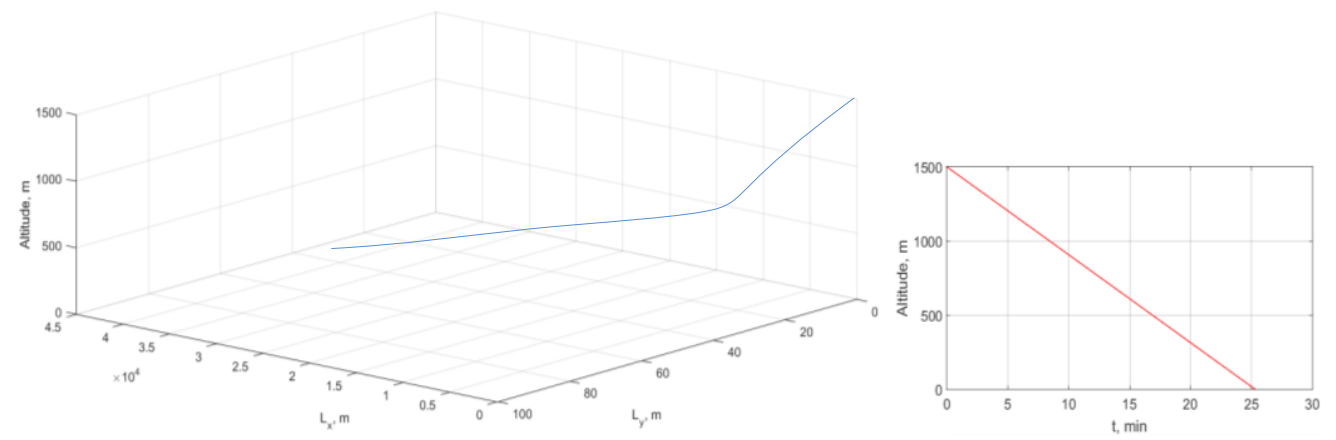

Figure 9. FLB flight path (right graph) and time (left graph).

\section{FLB Search and Recovery}

During regular contacts with ground personnel combat support aircraft crew reports its flight path. In case of its loss only few LPs around its last reported location undergo the initial scan. To pinpoint potential FLB LP a specialized tool is introduced. Its code incorporates FLB flight dynamics with Google maps API. In Figure 10 a screenshot of a user-friendly graphical interface is captured, where the demonstrated scenario simulates AF447 highlighting the crash location and the chosen LP. Traffic controller or SAR team member due to run such a software and further predicted LP to SAR team. Note that despite its commercial nature, the demonstrated AF447 scenario offers realistic background and inputs for an illustrative system operation. Real AF447 crash coordinates were imported from the BEA final report (Bureau of Enquiry and Analysis for Civil Aviation Safety, 2012). Further improvement of the tool aims at FLB location tracking with respect to real-time weather conditions. This is because both hourly wind magnitude and direction as well as the normal drifting by sea and ocean waves $(1-1.5 \mathrm{~km} / \mathrm{h})$ in case if LP is projected on water surface should be input. Over time, those natural factors drift FLB in line with the direction of sea waves the matter that must be considered during delayed searches.

FLB transmits $100 \mathrm{~km}$ range signals to guide search teams towards its LP (see the green circle). A special FLB signal receiver is used to receive them.

Search and Rescue (SAR) operations may employ rotary vehicles such as Sikorsky S-92 medium-range ( 600km) helicopters (Bristow Group Inc., 2017) and/or marine vessels, e.g. John Lethbridge Vessel for long-range (>600km) (Global Marine Systems Ltd., 2010) and should prioritize FLB localization. Accordingly, this technique directs search campaigns to check rigid points instead of scanning vast areas saving search time and cost. As such, shift to discretized SAR operation seems more efficient option for FLB localization and recovery.

FLB retrieval and unsealing is regarded the responsibility of air safety officers who conduct same-day flight data analysis and mother-aircraft crash localization. An alternate technique suggests FLB interactivity provision enabling remote flight command transmission via FLB signal receiver. 
Though it may seem functional, system complication, potential FLB loss and structural damages shrink the range of real field implementation of this supplement.

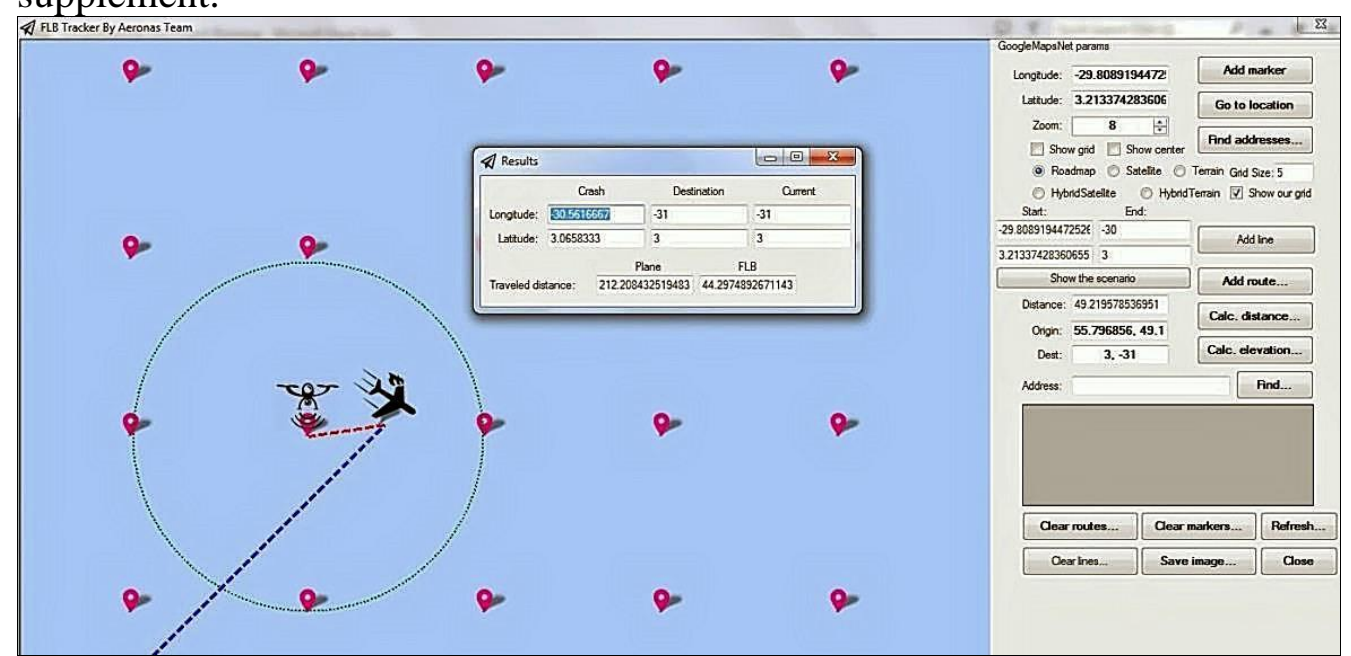

Figure 10. Simulation of AF447 showing suggested LP (the green circle shows FLB RF signals)

While operating in hostile unpredictably dynamic environments FLB is susceptible to various malfunctions. First may be resulted by mother-aircraft empennage deformation or failure following an air-to-air or ground-to-air warhead impact. In this scenario ES or FLB key elements may suffer fatal damages. Due to its weak thermal fingerprint and dimensions flying, FLB is unlikely to be persuaded and downed by these missiles. A second concern is tail cone structural damages after rough takeoff or landing with tailstrike. Similar events may affect FLB airframe or inner connections, but they should impose the least damage to the internal well-protected chip memory. In case of in/near runway crashes, where FLB ejection likely fails due to zero or small $H$, FDR and CVR along with aircraft wreckage will definitely scatter close to SAR teams eliminating the need of FLB.

However, although RF location broadcast may guide unfriendly parties to FLB, sometimes, leading to compromise sensitive data, location of the wreckage or endanger surviving crew in the vicinity this approach shows off as a double-edged solution. Similar scenarios may also end up saving crew lives in case of hospitalization of injured members by either neutral and ally forces or even by hostile forces. Indeed, only field application may establish some statistical conclusion regarding its value.

\section{Conclusion}

An overview on flight data protection and recovery project has been provided. As concluded, quick access to combat support aircraft crash locations will reduce time and cost of search operations without using spacebased means or long-range real-time communications. Alternatively, this 
concept proposes an innovative approach for rapid extraction of backup flight data before the impact implementing UAS capabilities so as to enable sameday flight data analysis and significant shortening of search process by covering only limited fixed LPs, which eventually accelerates the release of final reports and safety recommendations. Comparison between the proposed approach and the main available solutions, see (Bureau of Enquiry and Analysis for Civil Aviation Safety, 2009), is included below in Table 2 highlighting advantageous flight data recoverability and aircraft wreckage localization. The significantly FLB high cost is attributed to the required advanced research and development prior to final certification.

Table 2

Available and proposed technologies applicable for tracking missed combat support aircraft

\begin{tabular}{|c|c|c|}
\hline \multirow[b]{2}{*}{ Technology } & \multicolumn{2}{|c|}{ Comparison criteria } \\
\hline & $\begin{array}{l}\text { A) Flight data } \\
\text { recoverability; } \\
\text { B) Contribution to } \\
\text { flight recorders } \\
\text { localization. }\end{array}$ & $\begin{array}{l}\text { A) Cost range; } \\
\text { B) Technology maturity; } \\
\text { C) Available Equipage } \\
\text { Installation. }\end{array}$ \\
\hline $\begin{array}{c}\text { Automatic or } \\
\text { triggered by } \\
\text { catastrophic scenario } \\
\text { real time flight main } \\
\text { parameters } \\
\text { transmission } \\
\end{array}$ & $\begin{array}{l}\text { A.1) Encrypted \& } \\
\text { exclusive. } \\
\text { A.2) Only for non- } \\
\text { military mission. } \\
\text { B.1) Limited by A.2. }\end{array}$ & $\begin{array}{l}\text { A) }>10 \mathrm{~K}-250 \mathrm{~K} \$ \text {. } \\
\text { B) Completely developed } \\
\text { and tested. } \\
\text { C) Some of on-board / } \\
\text { ground. }\end{array}$ \\
\hline $\begin{array}{l}\text { Automatic position } \\
\text { reporting (ADS-B) }\end{array}$ & $\begin{array}{l}\text { A.1) Only for non- } \\
\text { military flights. } \\
\text { B.1) Limited by A.1. }\end{array}$ & $\begin{array}{l}\text { A) } 10 \mathrm{~K}-250 \mathrm{~K} \$ \text {. } \\
\text { B) Completely/partially } \\
\text { developed and tested. } \\
\text { C) Some of on-board and } \\
\text { ground. }\end{array}$ \\
\hline $\begin{array}{lr}\text { Transmission } & \text { of } \\
\text { flight parameters in } \\
\text { ACARS failure or } \\
\text { AOC ACARS and } \\
\text { military analogues } \\
\text { position report } \\
\text { messages }\end{array}$ & $\begin{array}{l}\text { A.1) Partially } \\
\text { Encrypted \& } \\
\text { exclusive. } \\
\text { A.2) Only for non- } \\
\text { military flights. } \\
\text { B.1) Limited by A.2. }\end{array}$ & $\begin{array}{l}\text { A) } 10 \mathrm{~K}-250 \mathrm{~K} \$ \text {. } \\
\text { B) Completely developed } \\
\text { and tested. } \\
\text { C) Both on-board and } \\
\text { ground. }\end{array}$ \\
\hline $\begin{array}{l}\text { Single/double ED- } \\
112, \text { ED-155 } \\
\text { combined free- } \\
\text { floating deployable } \\
\text { recorder }\end{array}$ & $\begin{array}{l}\text { A.1) Restricted by } \\
\text { wreckage localization. } \\
\text { B.1) Limited by } \\
\text { mission type. }\end{array}$ & $\begin{array}{l}\text { A) }<10 \mathrm{~K} \$ \text { for ED-112; } \\
>250 \mathrm{~K} \$ \text { for ED-155. } \\
\text { B) Completely/partially } \\
\text { developed and tested. } \\
\text { C) Some of on-board and } \\
\text { ground. }\end{array}$ \\
\hline
\end{tabular}




\begin{tabular}{|c|c|c|}
\hline $\begin{array}{c}\text { Improved } \\
\text { attachment and } \\
\text { autonomy of ULBs }\end{array}$ & $\begin{array}{l}\text { A.1) Outside functions } \\
\text { list. } \\
\text { B.1) High. } \\
\text { B.2) Within 30-90 } \\
\text { days. }\end{array}$ & $\begin{array}{l}\text { A) }<10 \mathrm{~K} \$ \text {. } \\
\text { B) Completely developed } \\
\text { and tested. } \\
\text { C) Some of on-board and } \\
\text { ground. }\end{array}$ \\
\hline $\begin{array}{l}\text { Long-range low } \\
\text { frequency ULBs, } \\
\text { trackable by military } \\
\text { ships. }\end{array}$ & $\begin{array}{l}\text { A.1) Outside functions } \\
\text { list. } \\
\text { B.1) High. } \\
\text { B.2) Within 30-90 } \\
\text { days. }\end{array}$ & $\begin{array}{l}\text { A) } 10 \mathrm{~K}-250 \mathrm{~K} \$ \text {. } \\
\text { B) Completely developed } \\
\text { and tested. } \\
\text { C) Limited. }\end{array}$ \\
\hline $\begin{array}{l}\text { Remotely triggered } \\
\text { ULB transmission }\end{array}$ & $\begin{array}{l}\text { A.1) Outside functions } \\
\text { list. } \\
\text { B.1) High. } \\
\text { B.2) > } 90 \text { days. }\end{array}$ & $\begin{array}{l}\text { A) } 10 \mathrm{~K}-250 \mathrm{~K} \$ \text {. } \\
\text { B) Completely developed } \\
\text { and tested. } \\
\text { C) Limited. }\end{array}$ \\
\hline Deployable ELTs & $\begin{array}{l}\text { A.1) Outside functions } \\
\text { list. } \\
\text { B.1) High. } \\
\text { B.2) Within 30-90 } \\
\text { days. }\end{array}$ & $\begin{array}{l}\text { A) }>250 \mathrm{~K} \$ \text {. } \\
\text { B) Completely developed, } \\
\text { tests needed. } \\
\text { C) Some of on-board and } \\
\text { ground. }\end{array}$ \\
\hline FLB & $\begin{array}{l}\text { A.1) High (backup } \\
\text { flight data). } \\
\text { A.2) SOS signals } \\
\text { (international) } \\
\text { B.1) High. } \\
\text { B.2) Within 30-90 } \\
\text { days. }\end{array}$ & $\begin{array}{l}\text { A) >> } 250 \mathrm{~K} \$ \text {. } \\
\text { B) Partially developed (i.e. } \\
\text { essential elements), tests } \\
\text { needed. } \\
\text { C) Some of on-board and } \\
\text { ground. }\end{array}$ \\
\hline
\end{tabular}

On the long term, a successful well-validated integration of FLB technology with current FDR and CVR may lead to the replacement of the latter.

\section{Acknowledgement}

This work is initially proposed and developed within the framework of Airbus international contest "Fly Your Ideas 2017". We are grateful to Airbus experts Laurent B. and Laval C. for their supervision and valuable discussions on FLB design criterions, ejection system maintainability and overall operation optimization. 


\section{References}

ADS-B Exchange. (2017). Currently airborne military aircraft. Retrieved from https://www.adsbexchange.com/airborne-military-aircraft/

Australian Air Transport Safety Bureau. (2017). The operational search for MH370. Retrieved from https://www.atsb.gov.au/media/ 5773565/operational-search-for-mh370_final_3oct2017.pdf

Aviation Library. (2017). Il-86 documentation and technical manuals. Retrieved from http://www.aviadocs.net/RLE/IL-86/

Aviation Safety Network. (2017). Aviation safety database. Retrieved from https://aviation-safety.net/database/

Bekhtir B. P. (1991). Prakticheskaya aerodinamika samoleta Il-86 (Eng. trans.: Airliner Il-86 Aerodynamic Performance), GA SEV-IPK Center, Ulyanovsk, Russia.

Bristow Group Inc. (2017). UK search and rescue fleet. Retrieved from bristowgroup.com/uk-sar/sar-fleet/

Bureau of Enquiry and Analysis for Civil Aviation Safety. (2012). Air France Flight 477 Final report. Bureau d'Enquêtes et d'Analyses pour la sécurité de l'aviation civile (BEA). Retrieved from https://www.bea.aero/docspa/2009/f-cp090601.en/pdf/fcp090601.en.pdf

Bureau of Enquiry and Analysis for Civil Aviation Safety. (2009). Flight data recovery working group final report. Bureau d'Enquêtes et d'Analyses pour la sécurité de l'aviation civile (BEA). Retrieved from https://www.bea.aero/uploads/tx_elyextendttnews/flight.data.recovery. working.group.final.report_03.pdf

Chemring Co. (2012). Pyromechanisms. Retrieved from http://www.chemring.co.uk/ /media/Files/C/ChemringV2/PDFs/sector-brochure-pyromechanisms-web-300512.pdf

Consumer News and Business Channel. (2017). Ejectable, floating 'black box' to be installed on long range Airbus planes. Retrieved from https://www.cnbc.com/2017/06/21/ejectable-floating-black-box-to-beinstalled-on-long-range-airbus-planes.html

Dhananjay B., Suraj D., \& Meenakshi G. (2015). A review on ejectable versus non-ejectable flight data recorder. International Journal of Science, Engineering and Technology Research (IJSETR), 4(6), 2273-2277. Retrieved from https://pdfs.semanticscholar.org/202c/ 1d654220fe306e992bcec5732e8632414667.pdf

Global Marine Systems Ltd. (2010). M.V. John Lethbridge. Retrieved from http://www.cablesm.fr/John\%20Lethbridge.pdf

FlightAware. (2016). Aireon and Flightaware partner to launch global beacon airline solution for ICAO airline flight tracking compliance. Retrieved from https://flightaware.com/news/article/Aireon-and-FlightAware- 
Partner-to-Launch-GlobalBeacon-Airline-Solution-for-ICAO-AirlineFlight-Tracking-Compliance/22

National Transportation Safety Board. (2017). Cockpit voice recorders (CVR) and flight data recorders (FDR). Retrieved from https://www.ntsb.gov/news/Pages/cvr_fdr.aspx

Parvathy R., \& Smith, H. (2014). The development of a small solar powered electric unmanned aerial vehicle systems. Applied Mechanics and Materials, 465-466, 345-351. https://doi.org/10.4028/ www.scientific.net/AMM.465-466.345

Vasquez, T. (2012). Air France Flight 447: A detailed meteorological analysis. Weather Graphics. Retrieved from http://www.weathergraphics.com/tim/af447/

Wang, S.-S., Hung, H.-S., Ho, J.-J., Lin, J.-X., \& Yeh, C.-H. (2015). Improving detection technique for flight recorders of the distress airplanes crashed into ocean by integrating inertial navigation system into underwater locator beacon. Journal of Marine Science and Technology, 23(4), 467-474. doi: 10.6119/JMST-014-1027-1 